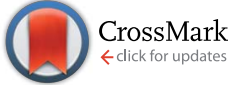

Cite this: RSC Adv., 2016, 6, 21795

Received 11th January 2016 Accepted 10th February 2016

DOI: 10.1039/c6ra00789a

www.rsc.org/advances

\section{A facile chemical method for the synthesis of 3C-SiC nanoflakes}

\author{
Mirela Dragomir, ${ }^{\star a b}$ Matjaz Valant, ${ }^{\text {ac }}$ Mattia Fanetti ${ }^{a}$ and Yurij Mozharivskyj ${ }^{\text {b }}$
}

A facile chemical method for the synthesis of $3 \mathrm{C}-\mathrm{SiC}$ nanoflakes is presented. The process involves the pyrolysis of polycarbosilane (PCS) at $700{ }^{\circ} \mathrm{C}$, in a $\mathrm{NaCl}$ powder template, followed by thermal treatment at $1200{ }^{\circ} \mathrm{C}$. The salt is easily removed by washing with water. The morphology of the SiC particles is found to be dependent on the NaCl/PCS weight ratio and by carefully tuning this ratio, different $\mathrm{SiC}$ structures can be obtained. While at NaCl/PCS ratios < 40:1 micrometer-sized particles with a foamy like structure result, a NaCl/PCS ratio of $40: 1$ is crucial for the formation of $3 \mathrm{C}-\mathrm{SiC}$ nanoflakes. These nanoflakes are less than 5 nanometers thick, have a high specific surface area of $169 \mathrm{~m}^{2} \mathrm{~g}^{-1}$ and a high total pore volume of up to $0.75 \mathrm{~cm}^{3} \mathrm{~g}^{-1}$. This method could open a simple, versatile and robust way for the production of $\mathrm{SiC}$ nanostructures. Such a facile synthetic method could bring nanostructured $\mathrm{SiC}$ one step closer to the ultimate goal of practical applications.

\section{Introduction}

The technological potential of nanostructured $3 \mathrm{C}-\mathrm{SiC}$ is enormous due to its exceptional properties such as high mechanical strength over weight ratio, chemical and thermal stability, biocompatibility, ${ }^{1-3}$ and low band gap ${ }^{4}$ of $2.4 \mathrm{eV}$ combined with a high value for electron mobility. ${ }^{5}$

Many novel properties and applications have been reported and predicted for nanosized 3C-SiC, such as nanoscale light emitters, ${ }^{6-9}$ photocatalysis, ${ }^{10-12}$ Li-ion batteries, ${ }^{13}$ hydrogen evolution and storage, ${ }^{14-17}$ support for graphene growth, ${ }^{18}$ for strengthened structural polymer nanocomposites, ${ }^{19,20}$ and others. ${ }^{21,22}$ In addition, a number of current technologies are standing by for a chance to introduce $\mathrm{SiC}$ nanopowder in their products immediately when it will be commercially viable. An example is the car tire industry where the SiC nanopowder as an additive to rubber could dramatically reduce wear and increase lifetime of the product.

It is surprising that despite the obvious technological potential and commercial interest, the synthesis of SiC nanostructures remains technologically complex and energy consuming. No facile methods for mass production of the SiC nanopowder have yet been developed. The limitations of the existing synthetic methods hinder the development of products and devices based on the nanostructured SiC.

Compared to oxide nanoparticles that require only mild synthetic conditions and simple procedures, far fewer synthetic

${ }^{a}$ Materials Research Laboratory, University of Nova Gorica, Nova Gorica, SI-5000, Slovenia.E-mail: mirela85.dragomir@gmail.com

${ }^{b}$ Department of Chemistry and Chemical Biology, McMaster University, 1280 Main Street West, Hamilton, Ontario, L8S 4M1, Canada

${ }^{c}$ University of Electronic Sciences and Technology of China, Institute of Fundamental and Frontier Science, North Jianshe Road No. 4 Section 2, Chengdu, 610054, China methods exist for the synthesis of non-oxide compounds such as $3 \mathrm{C}-\mathrm{SiC}$, despite all efforts and recent progress. The available synthetic approaches for nanosized $3 \mathrm{C}-\mathrm{SiC}$ such as pulsed laser ablation, ${ }^{23}$ arc discharge ${ }^{24}$ chemical vapour deposition, ${ }^{25}$ carbothermal reduction, ${ }^{26-30}$ or laser pyrolysisis ${ }^{31}$ suffer major disadvantages as they are technically demanding and require very high temperatures $\left(\gg 1500{ }^{\circ} \mathrm{C}\right)$, long reaction times or sophisticated and expensive equipment. Hence, during the last years, researchers' attention has been devoted to alternative synthetic routes that would enable economically viable mass production of $\mathrm{SiC}$ nanopowders. Alternative methods such as molten salt route, ${ }^{32}$ chemical etching in aqueous $\mathrm{HF}^{33}$ or pyrolysis of organosilicon polymers in nanotemplates have been reported. ${ }^{34,35}$ However, these methods have their drawbacks; they use expensive irrecoverable templates (e.g., nanosized silica $)^{36}$ or concentrated $\mathrm{HF}$ as an etching agent. Consequently, these approaches make the production of nanosized SiC unsustainable.

To address these issues, we developed a new route to obtain nanosized polycrystalline $3 \mathrm{C}-\mathrm{SiC}$ by a green and simple method, at temperatures as low as $1200{ }^{\circ} \mathrm{C}$. We start from a cheap, non-toxic material, polycarbosilane (PCS), and $\mathrm{NaCl}$ which acts as a template. $\mathrm{NaCl}$ is inert and can be easily removed by washing with water.

By carefully tuning the NaCl/PCS weight ratio, different SiC structures were obtained (Fig. 1).

\section{Experimental}

\section{Materials}

PCS was purchased from Nabond (MW $=1500-2500$ ), while tetrahydrofuran (THF, anhydrous, 99.7\%) and $\mathrm{NaCl}(99+\%)$ 


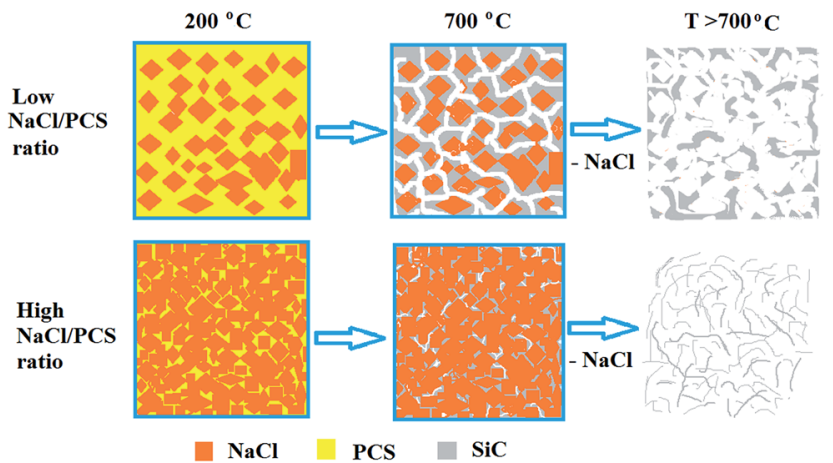

Fig. 1 Schematic representation of the process for the synthesis of $3 \mathrm{C}-\mathrm{SiC}$ nanoflakes in a $\mathrm{NaCl}$ powder template.

were purchased from Alfa Aesar. Ar (99.999\%) was used as the inert atmosphere. All the chemicals were used as received, without further purification.

In the typical synthesis procedure, $\mathrm{NaCl}$ was first manually ground and then soaked in a $5 \mathrm{wt} \%$ solution of PCS in THF to obtain a thick paste. After the THF evaporated, the $\mathrm{PCS} / \mathrm{NaCl}$ mixture was loaded into an alumina crucible and heated to $700^{\circ} \mathrm{C}$ under an Ar flow for $5 \mathrm{~h}$. In a parallel experiment, dry PCS was added to the $\mathrm{NaCl}$ powder and manually ground together for 30 minutes before being loaded in the furnace and heated under the same conditions. The resulted samples (consisting of pyrolyzed PCS and $\mathrm{NaCl}$ ) were washed several times with deionised $\mathrm{H}_{2} \mathrm{O}$ to remove the salt. A dark brown powder was recovered through centrifugation and was subsequently air dried at $55{ }^{\circ} \mathrm{C}$, for few hours. The collected powder (pyrolyzed PCS) was then heated to temperatures between $990-1200^{\circ} \mathrm{C}$ for different periods of time to promote the crystallisation of SiC. The yield of $\mathrm{SiC}$ was approximately $50 \mathrm{wt} \%$ with respect to the initial mass of PCS. Upon examination by scanning electron microscopy, no difference in morphology was observed when a PCS/THF solution or only dry PCS was used. Also, no difference in the morphology of the samples that were ground after the addition of PCS/THF solution and of the samples that were not ground after the $\mathrm{NaCl}$ was soaked with PCS/THF solution was noticed.

\section{Characterisation}

X-ray diffraction (XRD) analysis was performed with a PANalytical X'pert Pro diffractometer with $\mathrm{Cu} \mathrm{K}_{\alpha}$ radiation and an $\mathrm{X}$ 'celerator detector. The diffraction patterns were recorded in the 2-theta range from $20^{\circ}$ to $90^{\circ}$ with a step size of $0.5^{\circ}$ and a collection time of $100 \mathrm{~s}$ per step. The diffraction patterns were analyzed for the phase composition using H'Pert HighScore software. For the estimation of the crystallite size using the Scherrer equation, the full width at half maximum (FWHM) of the most intense peak was used.

The microstructure was investigated with a scanning electron microscope (SEM) model JEOL JSM 7100F, in a secondary electron mode. For this analysis, the samples were first dispersed in ethanol, then sonicated in an ultrasonic bath for 15 minutes. Afterwards, a drop of this dispersion was added onto a Si wafer. After the solvent evaporated, the Si wafer was fixed on the sample holder using a carbon tape. An accelerating voltage of $20 \mathrm{kV}$ was used for all the samples.

Transmission electron microscopy (TEM) analysis was performed with a transmission electron microscope model JEOL JEM $2100 \mathrm{HR}$, operating at $200 \mathrm{kV}$. For the TEM analysis, a dilute dispersion of SiC flakes in ethanol was first prepared. The dispersion was transferred to an ultrasonic bath for $15 \mathrm{~min}$ and then deposited on a lacey carbon-coated TEM grid by immersing the grid for few seconds in this dispersion and then air dried.

Fourier transform infrared (FT-IR) spectra were recorded in attenuated total reflectance (ATR) mode on a FT-IR spectrophotometer (Perkin Elmer Spectrum 100 FT-IR) equipped with TGS detector and an ATR module. For each measurement, the powder was pressed on the ATR (diamond) window $(d=2 \mathrm{~mm})$ and each spectrum was collected from 32 scans accumulation, each with a nominal resolution of $4 \mathrm{~cm}^{-1}$ in the region $400-$ $4000 \mathrm{~cm}^{-1}$. The background was measured with the ATR module without any sample.

The room temperature Raman spectra were recorded on the powder, in a $180^{\circ}$ backscattering geometry, after 10 recordings, with a Horiba Jobin-Yvon Lab RAM HR spectrometer equipped with a holographic notch filter and a CCD detector, by using the $632.8 \mathrm{~nm}$ excitation line of a $20 \mathrm{~mW}$ HeNe laser. The samples were placed on an Olympus BX 40 microscope equipped with a $50 \times$ objective and the laser beam was focused on the sample to give a spot size of $1 \mu \mathrm{m}$. The spectra were recorded in the range of $50-4000 \mathrm{~cm}^{-1}$.

The texture characteristics were determined by lowtemperature $(77.4 \mathrm{~K})$ nitrogen adsorption in a Quantachrome Instruments NOVA 1200e (USA) apparatus. The nitrogen adsorption-desorption isotherms were analyzed to evaluate the following parameters: the specific surface areas $\left(S_{\mathrm{BET}}\right)$ determined on the basis of the BET equation, the total pore volume $\left(V_{\mathrm{t}}\right)$ estimated in accordance with the Gurvich rule at a relative pressure close to 0.99 , and the pore size distribution (PSD) calculated using the BJH method.

\section{Results and discussions}

The microstructure of the as-obtained samples was investigated by SEM. It was found that the morphology of the particles changed drastically with the NaCl/PCS weight ratio. Big particles with dimensions ranging from $80-100 \mu \mathrm{m}$ formed when the $\mathrm{NaCl} / \mathrm{PCS}$ ratio was $1: 1$ (Fig. 2A). These particles were microcracked but with some smooth surfaces formed at the faces of the $\mathrm{NaCl}$ crystallites.

As the $\mathrm{NaCl} / \mathrm{PCS}$ ratio increased to $5: 1$, the particles size decreased to about $60 \mu \mathrm{m}$ (Fig. 2B). The morphology changed so that the particles show cavities with non-uniform shapes and volumes reflecting the morphology of the $\mathrm{NaCl}$ template. With the increase in the NaCl/PCS ratio to $10: 1$ (Fig. 2C), the mean particle size decreased to about $20 \mu \mathrm{m}$. In this case, the particles have a foamy-like structure. The morphology remained the same for the ratio of $20: 1$ (Fig. 2D). It appears that the cell walls become thinner as bigger cavities are formed. At a further 

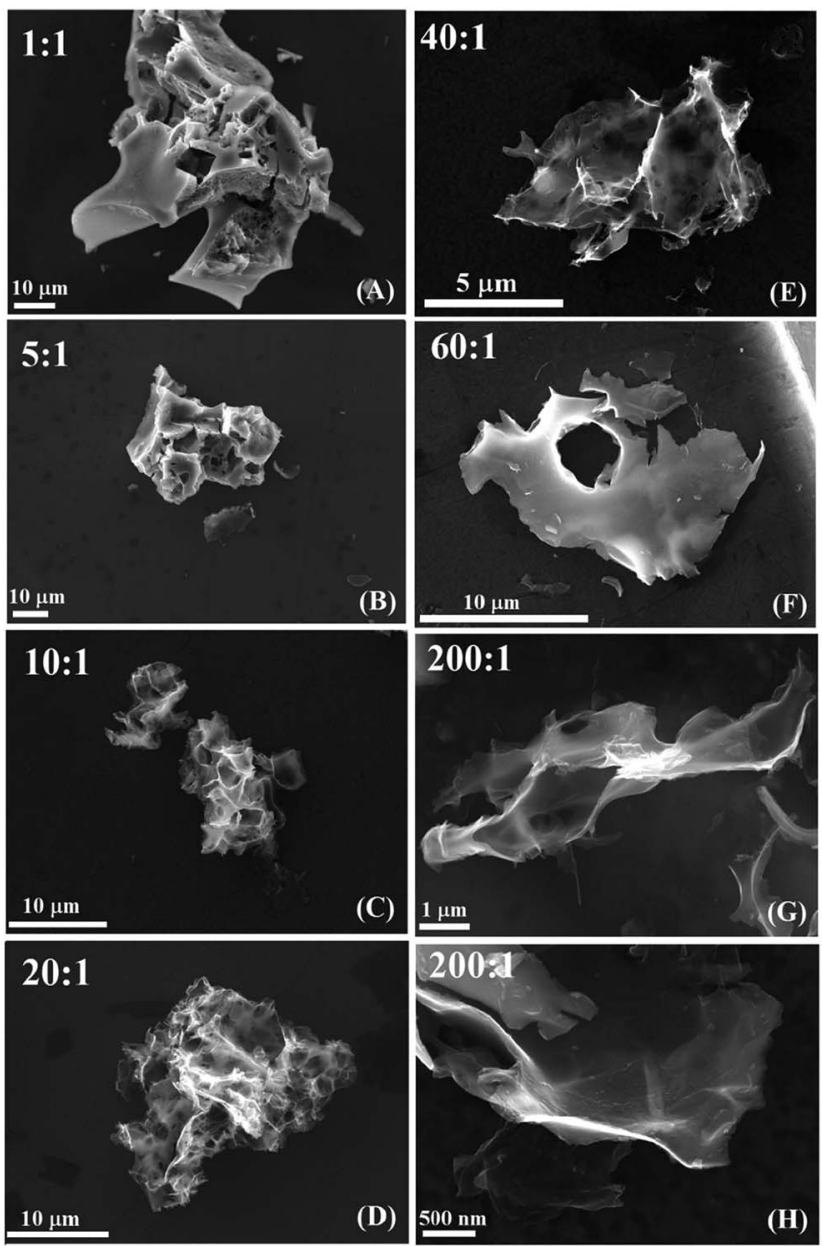

Fig. 2 SEM images of the SiC samples obtained by pyrolysis of PCS at different $\mathrm{NaCl} / \mathrm{PCS}$ ratios.

increase in the NaCl/PCS ratio to $40: 1$ the particles split to form a "W" shape (Fig. 2E).

For the NaCl/PCS ratio of $60: 1$, the particle size remained in the range of 5 to $10 \mu \mathrm{m}$. At this ratio, the particles look like thin flakes with some holes of few micrometers in diameter (Fig. 2F). No noticeable change in the morphology of the particles can be seen for the NaCl/PCS ratio of $200: 1$ (Fig. $2 \mathrm{G}$ and H). It is difficult to estimate the thickness of these flakes since they are non-uniform, but from the SEM analysis it can be approximated that they are about $5 \mathrm{~nm}$ at the edges and up to $50-60 \mathrm{~nm}$ in the thicker regions.

Aforementioned findings indicate the existence of a critical $\mathrm{NaCl} / \mathrm{PCS}$ ratio of about $40: 1$, at which the sheet-like structure of the SiC particles prevails. We assume that the reason behind this is a critical film thickness of the melted PCS film. Below this thickness, the liquid film ruptures.

To estimate this value, a theoretical critical film thickness of the liquid PCS on the $\mathrm{NaCl}$ surfaces, $h_{\mathrm{c}}$, was calculated using an equation developed by Manev and Nguyen ${ }^{37}$ (eqn (1)):

$$
h_{\mathrm{c}}=\left(A \lambda_{\mathrm{c}}{ }^{2} / 128 \sigma\right)^{1 / 4}
$$

where $A$ is the non-retarded Hamaker constant, $\lambda_{\mathrm{c}}$ is a critical wavelength which can be approximated with $1 / r,(r$ is the film radius) and $\sigma$ is the surface tension. Assuming that $r$ of a $\mathrm{NaCl}$ particle (with the diameter of a $\mathrm{NaCl}$ particle of about $40 \mu \mathrm{m}$, as in Fig. 3) is $20 \mu \mathrm{m}$, and that the surface tension $\sigma$ has a value of about 22 dynes $\mathrm{cm}^{-1}\left(\mathrm{~mJ} \mathrm{~m}^{-2}\right)$, for which a Hamaker constant $A$ is about $10-20 \mathrm{~J}$, then from the eqn (1) results that the $h_{\mathrm{c}}$ will have a value of $11 \mathrm{~nm}$. This value represents the thickness of the polymer film before the pyrolysis. Due to the polymer to ceramic conversion, this thickness will further decrease down to few nanometers. Indeed, as SEM analysis revealed, the smallest SiC flake thickness is below $5 \mathrm{~nm}$.

Fig. 4 shows the XRPD patterns of the samples obtained when the pyrolysed PCS (NaCl/PCS ratio of $40: 1)$ was heated at different temperatures, in Ar flow. It can be seen that the XRD pattern of the SiC flakes obtained at a temperature of $990{ }^{\circ} \mathrm{C}$ shows only a broad peak at 2-theta of $31.7^{\circ}$ and this indicates that the flakes obtained at this temperature are amorphous.

At $1000{ }^{\circ} \mathrm{C}$, a long-range order starts to develop as it is suggested by the onset of sharpening of this peak. As expected, a further increase in temperature to $1200{ }^{\circ} \mathrm{C}$ leads to a notable difference in the XRD patterns. At this temperature, three peaks that correspond to the characteristic planes of 3C-SiC, (111),

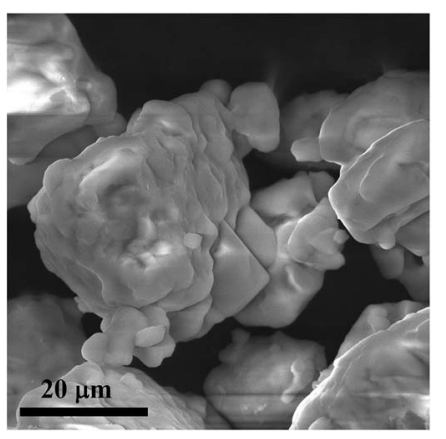

Fig. 3 A SEM image of the $\mathrm{NaCl}$ particles used in the synthesis of the $\mathrm{SiC}$ nanometer thin flakes.

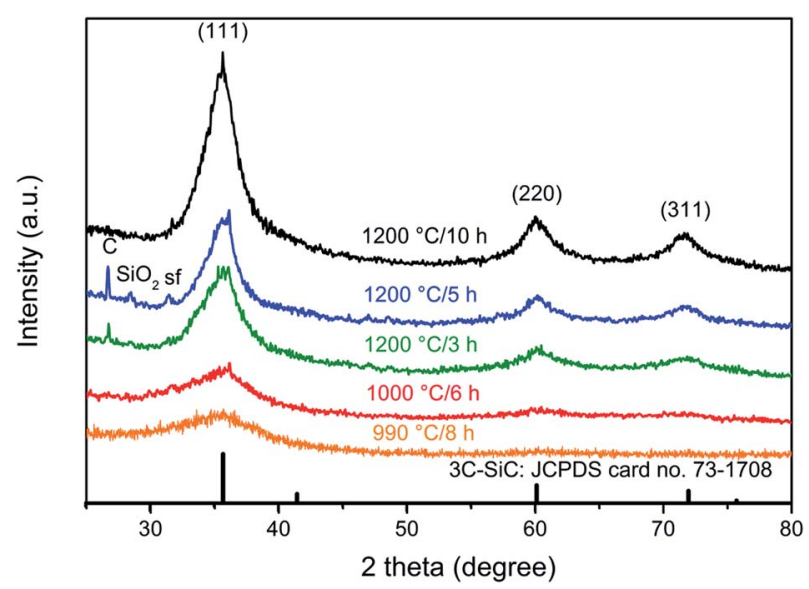

Fig. 4 XRPD patterns of the solids resulted when the pyrolysed PCS (from a NaCl/PCS ratio of $40: 1$ ) was heated at different temperatures, in $\mathrm{Ar}$ flow. 
(220), and (311) are clearly visible. As indicated by the broadness of the SiC diffraction peaks, the thermal treatment at $1200{ }^{\circ} \mathrm{C}$ for $3 \mathrm{~h}$ results in a $\mathrm{SiC}$ with a poor crystallinity and very small crystallite size.

With the increase in the dwell time to $5 \mathrm{~h}$ and $10 \mathrm{~h}$, a further increase in the crystallinity and growth of the crystal size occurs as it is suggested by the more intense and sharper diffraction peaks. The mean crystallite size for the sample obtained at 1200 ${ }^{\circ} \mathrm{C} / 10$ h was calculated with Scherrer equation ${ }^{38}$ (it was assumed that the peak broadening was caused only by the grain size, the microstrain and inhomogeneity of the sample were neglected) and it was found to be $3.65 \mathrm{~nm}$.

Two additional small peaks corresponding to carbon and $\mathrm{SiO}_{2}$ phases are also noticeable but only for the samples obtained at $1200{ }^{\circ} \mathrm{C}$ after 3 and $5 \mathrm{~h}$, respectively. It is well-known that the conversion of PCS to SiC will always result in the formation of residual carbon and some $\mathrm{SiO}_{2}-$ usually as a protective silica layer on the $\mathrm{SiC}$ material. ${ }^{39}$ While the presence of $\mathrm{C}$ is due to a nonstoichiometric $\mathrm{C} / \mathrm{Si}$ ratio in the $\mathrm{PCS}, \mathrm{SiO}_{2}$ can result from absorption of oxygen or moisture in raw PCS or oxygen entering the system during pyrolysis.

Judging only from the XRD analysis, one can see that the sample obtained at $1200{ }^{\circ} \mathrm{C} / 10 \mathrm{~h}$ is composed of only $3 \mathrm{C}-\mathrm{SiC}$. No impurities are detected for this sample, only one additional small peak located at 2-theta of $31.7^{\circ}$, which corresponds to the staking faults, sf. Sf are the most common defects in $3 \mathrm{C}-\mathrm{SiC}$ and they are regions of incorrect stacking of the crystal planes or twin boundaries. ${ }^{\mathbf{4 0 , 4 1}}$ However, evidence for the presence of some turbostratic $\mathrm{C}$ in this sample was later found from TEM and Raman analyses.

To further investigate the microstructure and phase composition of the SiC flakes, TEM, Raman, and IR analyses were performed. TEM images on the SiC samples obtained at different temperatures are shown in Fig. 5-8.

Fig. 5A-D shows a selection of TEM and HRTEM (as insets) images of samples obtained at different temperatures and dwell times. At a temperature of $1000{ }^{\circ} \mathrm{C} / 6 \mathrm{~h}$ (Fig. 5A) the samples look

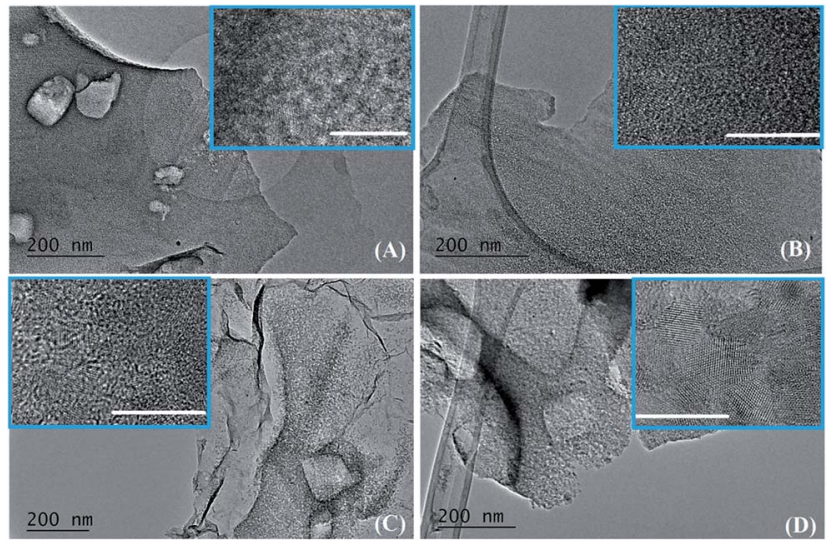

Fig. 5 TEM images of the SiC flakes obtained from a $\mathrm{NaCl} / \mathrm{PCS}$ ratio of $40: 1$, heated at different temperatures and for different periods of time: $1000^{\circ} \mathrm{C} / 6 \mathrm{~h}(\mathrm{~A}), 1200^{\circ} \mathrm{C} / 3 \mathrm{~h}(\mathrm{~B}), 1200^{\circ} \mathrm{C} / 5 \mathrm{~h} \mathrm{(C)}$, and $1200^{\circ} \mathrm{C} / 10$ $h$ (D). The insets are a high magnification image on the corresponding flake. The scale bar in all the insets is $10 \mathrm{~nm}$.

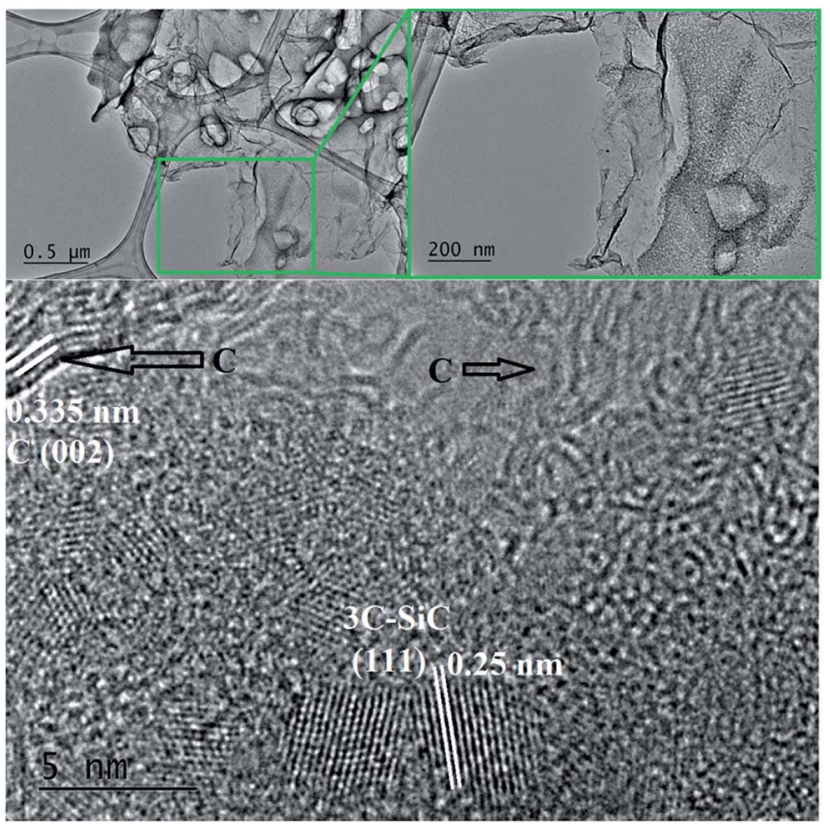

Fig. 6 TEM images of a SiC flake obtained at $1200{ }^{\circ} \mathrm{C} / 5 \mathrm{~h}$, from a $\mathrm{NaCl} / \mathrm{PCS}$ ratio of $40: 1$.

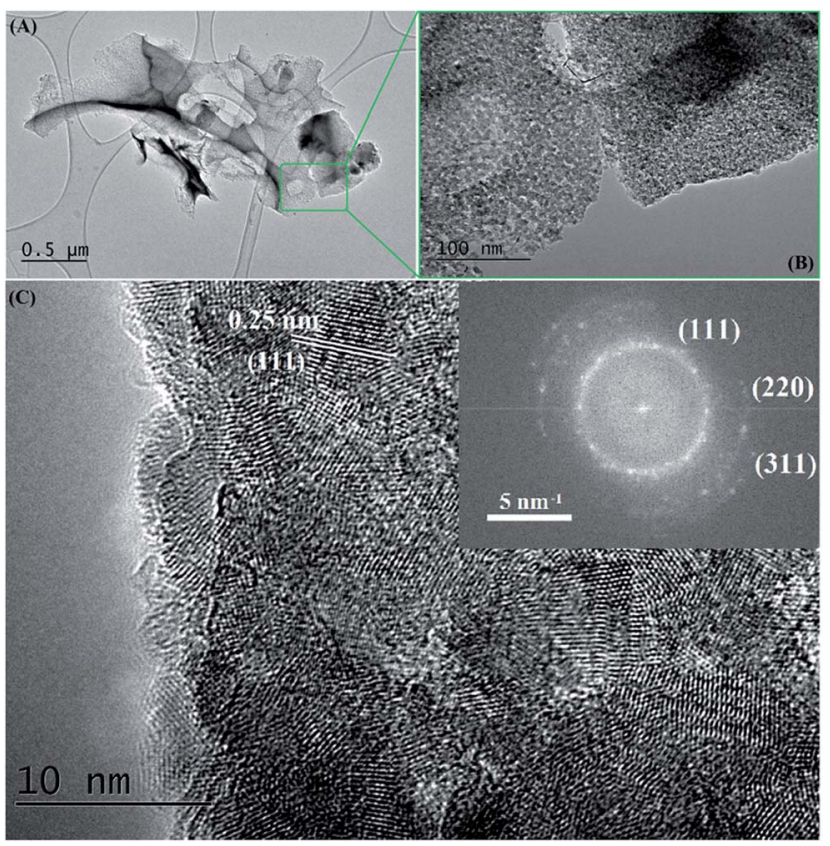

Fig. 7 TEM images of a SiC flake obtained at $1200{ }^{\circ} \mathrm{C} / 10 \mathrm{~h}$, from a $\mathrm{NaCl} / \mathrm{PCS}$ ratio of $40: 1$. The inset is the corresponding fast Fourier transform pattern.

like thin sheets with some rectangular holes (produced after the deionised water washed away the $\mathrm{NaCl}$ particles) and there is no obvious long-range order (see the inset in Fig. 5A).

A higher temperature of $1200{ }^{\circ} \mathrm{C}$ with a dwell time of $3 \mathrm{~h}$ does not result in a significant change of the texture or crystallinity. In the inset in Fig. 5B there is though a suggestion of some embryonic ordering from the presence of few SiC crystalline 


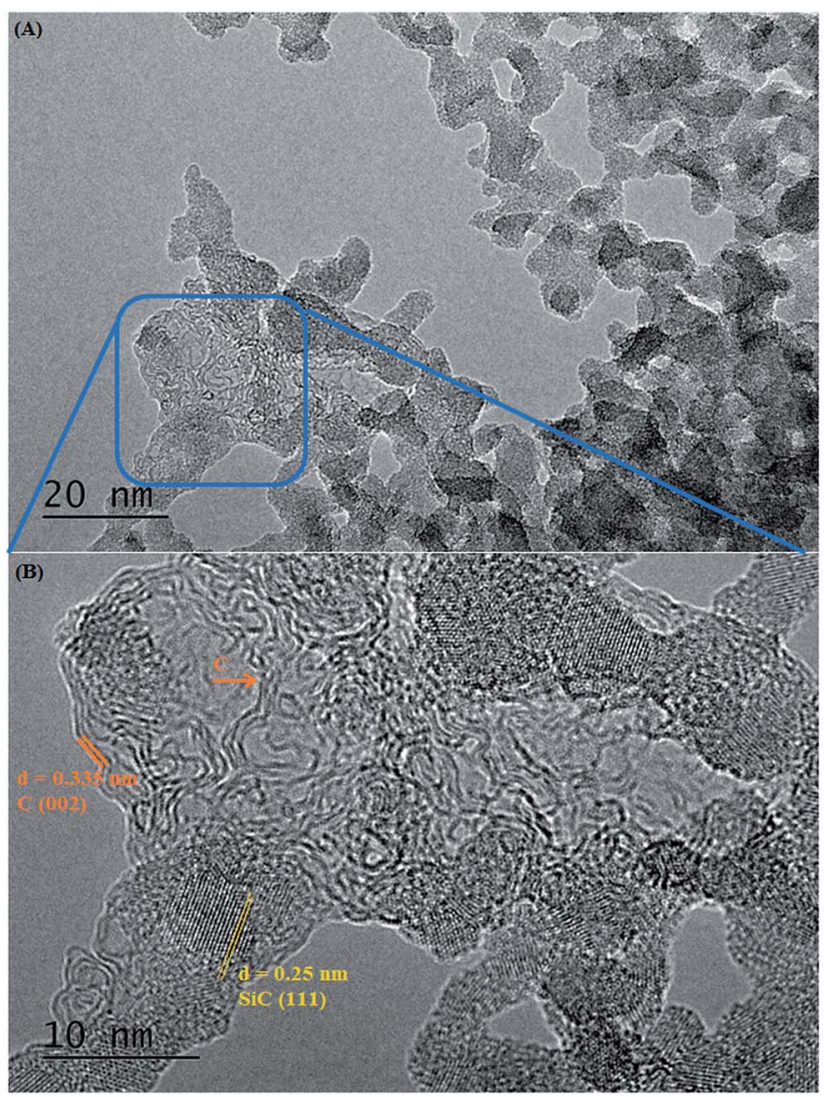

Fig. 8 (A) Additional TEM image of a SiC flake obtained at $1200^{\circ} \mathrm{C} / 10$ $\mathrm{h}$ from a NaCl/PCS ratio of 40 : 1; (B) this HRTEM image shows that an additional phase with the interplanar distance of $0.335 \mathrm{~nm}$ (carbon) is sometimes observed among the $\mathrm{SiC}$ nanocrystals.

areas in an amorphous matrix. A further small increase in the dwell time from 3 to $5 \mathrm{~h}$ leads to a drastic change in both texture and crystallinity. Fig. 5C clearly shows the presence of small crystallites in a thin sheet-like matrix. A closer look at the inset in Fig. 5C reveals that those spots are circular crystalline structures of about $2 \mathrm{~nm}$ in diameter with clearly visible lattice fringes. After $10 \mathrm{~h}$ at $1200{ }^{\circ} \mathrm{C}$, these crystallites grew to a size of about $4 \mathrm{~nm}$ and became interconnected as a result of the complete crystallisation and crystal growth (Fig. 5D). TEM analysis is in agreement with the XRD data which showed that the crystallinity of the samples increases progressively with increasing the dwell time from 3 to $10 \mathrm{~h}$ at $1200{ }^{\circ} \mathrm{C}$. Additional TEM images on the SiC flakes thermally treated at $1200{ }^{\circ} \mathrm{C} / 5 \mathrm{~h}$ are shown in Fig. 6. These images of SiC flakes freely suspended on a lacey carbon coated TEM grid further confirm their sheetlike morphology. The SiC samples also have few voids which were probably produced after the deionised water washed away the $\mathrm{NaCl}$ particles. Nanocrystallites of $3 \mathrm{C}-\mathrm{SiC}(d=0.25 \mathrm{~nm})$ with an average size of $2.7 \mathrm{~nm}$ (determined with the Image software) and different forms of carbon (turbostratic and onionlike carbon, with $d=0.335 \mathrm{~nm}$ ) can also be observed in these images.

Bright field TEM images of the sample obtained at the same temperature of $1200{ }^{\circ} \mathrm{C}$ but with a $10 \mathrm{~h}$ dwell time are shown in
Fig. 7. At a closer look (Fig. 7B), it can be seen that the flake is polycrystalline and it is composed only of SiC crystallites with average size $3.7 \mathrm{~nm}$ (most of them being between $2-5 \mathrm{~nm}$ ), value which is in excellent agreement with the crystallite mean size calculated by XRD $(3.65 \mathrm{~nm})$. Crystallites are randomly oriented and different orientations are observed in the TEM image, distinguishable from different interplanar distances $(0.25 \mathrm{~nm}$ for the (111) plane but also along the (220) and (311) planes) as shown in the corresponding Fast Fourier Transform (FFT) pattern (in the inset of the Fig. 7C). Additional TEM analyses on a different part of this flake (Fig. 8) show that some of the flakes are composed not only of 3C-SiC nanocrystallites $(d=0.25 \mathrm{~nm})$, but also graphene-like or onion-like carbon (with $d=0.335 \mathrm{~nm}$ ).

Raman analysis (Fig. 9) also suggests that some free carbon is present in this sample. In Fig. 9, the two Raman spectra (for the sample obtained at $1000{ }^{\circ} \mathrm{C} / 6 \mathrm{~h}$ and after crystallisation $\left.1200{ }^{\circ} \mathrm{C} / 10 \mathrm{~h}\right)$ look very similar. The amorphous sample (1000 ${ }^{\circ} \mathrm{C} / 6 \mathrm{~h}$ ) shows two main peaks at 1322 and $1603 \mathrm{~cm}^{-1}$, plus some small peaks at around 458, 611, 864, 959, 1160, 2623 and $2911 \mathrm{~cm}^{-1}$. The band located at $1160 \mathrm{~cm}^{-1}$ corresponds to the $\nu_{1}$ mode of transpolyacetylene; $;^{\mathbf{4 2 , 4 3}}$ at $1322 \mathrm{~cm}^{-1}$ is the D band of carbon (so called "disorder" band) which corresponds to the zone center phonons of $\mathrm{E}_{2 \mathrm{~g}}$ symmetry and it is associated with the structural imperfections or symmetry loss. The peak at 1603 $\mathrm{cm}^{-1}$ is the $\mathrm{G}$ (or graphitic) mode which is assigned to the $\mathrm{A}_{1 \mathrm{~g}}$ mode (in plane vibrational mode) of carbon. The peak at 2623 $\mathrm{cm}^{-1}$ is a second order overtone of the $\mathrm{D}$ mode (also named "2D") whereas the peak at $2911 \mathrm{~cm}^{-1}$ is the $\mathrm{D}^{\prime}$ or D + G peak (a combination scattering peak). An increase in the temperature to $1200{ }^{\circ} \mathrm{C}$ resulted in disappearance of the peak at $1160 \mathrm{~cm}^{-1}$, a redshift of the $G$ peak from 1603 to $1589 \mathrm{~cm}^{-1}$, and a narrowing of both $D$ and $G$ peaks. The redshift and narrowing of the $\mathrm{G}$ peak might indicate an increase in the ordering of the carbon phase. ${ }^{44}$ The $I_{\mathrm{D}} / I_{\mathrm{G}}$ ratio ( $I$ is the intensity of the peak) is related to the degree of carbon amorphisation. ${ }^{45}$ In our case, the $I_{\mathrm{D}} / I_{\mathrm{G}}$ ratio is having a value of 1.43 and 1.37 , for the amorphous and crystalline SiC,

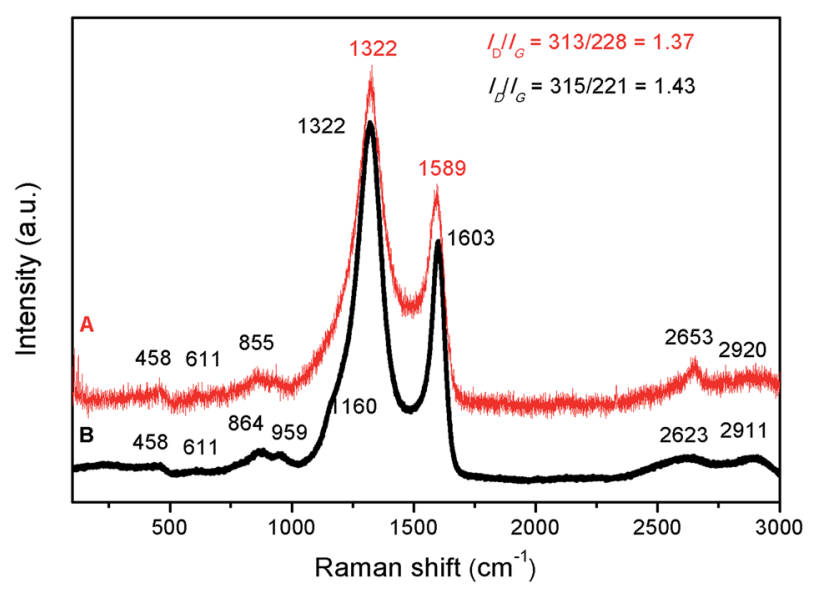

Fig. 9 Raman spectra of $\mathrm{SiC}$ samples obtained at two different temperatures, before $\left(1000{ }^{\circ} \mathrm{C} / 6 \mathrm{~h}\right.$ - spectrum B) and after crystallisation $\left(1200^{\circ} \mathrm{C} / 10 \mathrm{~h}\right.$ - spectrum A). 


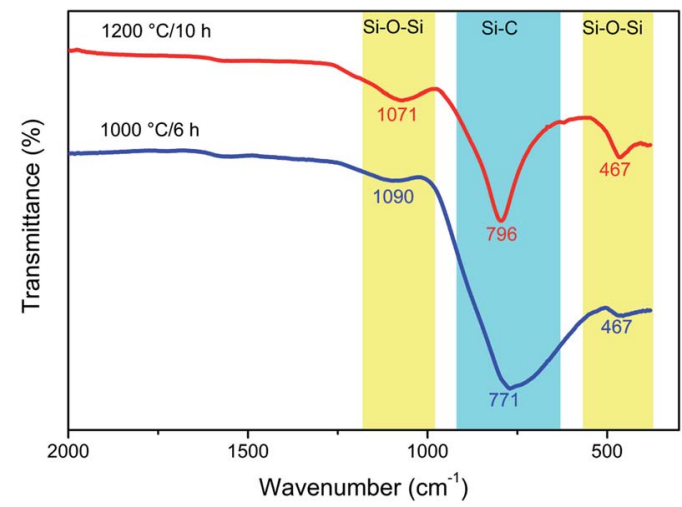

Fig. 10 ATR spectra of two SiC samples obtained at two different temperatures, before $\left(1000{ }^{\circ} \mathrm{C} / 6\right.$ h) and after $\left(1200{ }^{\circ} \mathrm{C} / 10 \mathrm{~h}\right)$ crystallisation.

respectively and this further suggests that in both samples, the carbon could exist in the form of few graphene layers.

The small peaks located at 458 and $611 \mathrm{~cm}^{-1}$ correspond to the $\mathrm{Si}-\mathrm{O}-\mathrm{Si}$ bonds, whereas the ones located at about 860 and $959 \mathrm{~cm}^{-1}$ are probably the TO and LO Raman modes of SiC. Due to a better Raman scattering efficiency of the $\mathrm{C}-\mathrm{C}$ bonds compared to the $\mathrm{Si}-\mathrm{C}$ ones, and for such small $\mathrm{SiC}$ crystallites, the Raman lines characteristic of crystalline SiC become almost unobservable. ${ }^{46}$ The residual carbon observed along with the $\mathrm{SiC}$ phase can be beneficial in photocatalytic processes where it can serve as electron-accepting sites, facilitating the interface charge separation. But if desired, this residual carbon can also be removed by heating in air at approximately $600{ }^{\circ} \mathrm{C}$.

ATR analysis of the samples obtained at $1000{ }^{\circ} \mathrm{C} / 6 \mathrm{~h}$ and $1200^{\circ} \mathrm{C} / 10 \mathrm{~h}$ (Fig. 10) shows that both samples consist of mainly SiC. At $1000{ }^{\circ} \mathrm{C}$, a broad absorption band at $771 \mathrm{~cm}^{-1}$ and two small shoulders at 467 and $1090 \mathrm{~cm}^{-1}$ are observed. The strongest band $\left(771 \mathrm{~cm}^{-1}\right)$ corresponds to the $\mathrm{Si}-\mathrm{C}$ bond stretching mode, while the weak absorption bands (467 and $1090 \mathrm{~cm}^{-1}$ ) could be assigned to Si-O symmetric and asymmetric stretching modes. With an increase in temperature to $1200{ }^{\circ} \mathrm{C}$ and, therefore, an increase in the crystallinity, these bands become narrower. As also indicated by ATR analysis, the $\mathrm{SiC}$ obtained at $1200{ }^{\circ} \mathrm{C} / 10 \mathrm{~h}$ contains a very small amount of silicon dioxide. This $\mathrm{SiO}_{2}$ can be removed by washing with a small amount of diluted hydrofluoric acid. ${ }^{47}$

To obtain quantitative morphologic information about the samples, nitrogen adsorption was measured at $77.4 \mathrm{~K}$. The specific surface area was calculated using the BET method $\left(S_{\mathrm{BET}}\right)$. The isotherms were analysed to determine the total pore volume $\left(V_{\mathrm{t}}\right)$ and the pore size distribution (PSD).

To investigate the effect of the $\mathrm{NaCl} / \mathrm{PCS}$ ratio on the $S_{\mathrm{BET}}$, fourteen samples were selected, as shown in Table 1.

As already revealed by SEM, the BET analyses indicate that a fine tuning of the $\mathrm{NaCl} / \mathrm{PCS}$ ratio clearly results in the evolution of diverse morphologies. For the samples obtained at the temperatures lower than the crystallisation temperature, the $S_{\mathrm{BET}}$ increased with the NaCl/PCS ratio from a value of $8 \mathrm{~m}^{2} \mathrm{~g}^{-1}$ (1:1 ratio) up to a maximum value of $163 \mathrm{~m}^{2} \mathrm{~g}^{-1}$ (200:1 ratio).
Table 1 Specific surface area, $S_{\mathrm{BET}}$, total pore volume, $V_{\mathrm{t}}$, and pore dimensions, $D$, of the samples obtained at $700{ }^{\circ} \mathrm{C} / 5 \mathrm{~h}$ (before crystallisation) and at $1200{ }^{\circ} \mathrm{C} / 10 \mathrm{~h}$ (after crystallisation) from different $\mathrm{NaCl} / \mathrm{PCS}$ ratios

\begin{tabular}{|c|c|c|c|c|c|c|}
\hline \multirow[b]{2}{*}{$\begin{array}{l}\mathrm{NaCl} \text { to PCS } \\
\text { weight ratio }\end{array}$} & \multicolumn{3}{|c|}{ Obtained at $700{ }^{\circ} \mathrm{C}$} & \multicolumn{3}{|c|}{ Obtained at $1200{ }^{\circ} \mathrm{C}$} \\
\hline & $\begin{array}{l}S_{\mathrm{BET}} \\
\left(\mathrm{m}^{2} \mathrm{~g}^{-1}\right)\end{array}$ & $\begin{array}{l}V_{\mathrm{t}}, \\
\left(\mathrm{cm}^{3} \mathrm{~g}^{-1}\right)\end{array}$ & $\begin{array}{l}D \\
(\mathrm{~nm})\end{array}$ & $\begin{array}{l}S_{\mathrm{BET}} \\
\left(\mathrm{m}^{2} \mathrm{~g}^{-1}\right)\end{array}$ & $\begin{array}{l}V_{\mathrm{t}}, \\
\left(\mathrm{cm}^{3} \mathrm{~g}^{-1}\right)\end{array}$ & $\begin{array}{l}D \\
(\mathrm{~nm})\end{array}$ \\
\hline $1: 1$ & 8 & 0.02 & 7 & 4 & 0.05 & 4.5 \\
\hline $5: 1$ & 13 & 0.02 & 5 & 9 & 0.01 & 5.8 \\
\hline $10: 1$ & 8 & 0.02 & 9.5 & 24 & 0.03 & 4.6 \\
\hline $20: 1$ & 10 & 0.02 & 10 & 64 & 0.10 & 6 \\
\hline $40: 1$ & 15 & 0.07 & 19 & 169 & 0.19 & 4.5 \\
\hline $60: 1$ & 21 & 0.09 & 16 & 68 & 0.12 & 7.2 \\
\hline $200: 1$ & 163 & 0.75 & 1.81 & 72 & 0.26 & 14 \\
\hline
\end{tabular}

This high $S_{\mathrm{BET}}$ is associated with a very high value of the $V_{\mathrm{t}}$ of $0.75 \mathrm{~cm}^{3} \mathrm{~g}^{-1}$. Also the $S_{\mathrm{BET}}$ of the crystalline samples increased with the NaCl/PCS ratio, from $4 \mathrm{~m}^{2} \mathrm{~g}^{-1}(1: 1)$ up to a value of 72 $\mathrm{m}^{2} \mathrm{~g}^{-1}(200: 1)$. When NaCl/PCS ratio was below $10: 1$, the $S_{\mathrm{BET}}$ of the SiC obtained at $1200{ }^{\circ} \mathrm{C}$ was lower than that at $700{ }^{\circ} \mathrm{C}$. At $1200{ }^{\circ} \mathrm{C}$, as the crystallisation occurs, $\mathrm{Si}-\mathrm{C}$ bonds rearrange to form a more dense structure which could lead to a decrease of the $S_{\mathrm{BET}}$. The samples obtained from a NaCl/PCS ratio $\geq 20: 1$ showed a bigger $S_{\mathrm{BET}}$ at $1200{ }^{\circ} \mathrm{C}$ than at $700{ }^{\circ} \mathrm{C}$, except for the sample obtained from a NaCl/PCS ratio of $200: 1$, which shows decreased $S_{\mathrm{BET}}$. It is interesting to observe that at $1200{ }^{\circ} \mathrm{C}$, the largest $S_{\mathrm{BET}}$ belongs to the sample obtained from a NaCl/PCS ratio of $40: 1$.

\section{Conclusions}

In this work, a facile synthetic route to $3 \mathrm{C}-\mathrm{SiC}$ nanoflakes by pyrolysis of PCS in a $\mathrm{NaCl}$ template at $700{ }^{\circ} \mathrm{C}$, followed by crystallisation at $1200{ }^{\circ} \mathrm{C}$, was developed. It was found that the weight ratio between $\mathrm{NaCl}$ and PCS is dictating the morphology of the SiC particles. A critical NaCl/PCS ratio for the formation of the nanoflakes has been determined to be around $40: 1$. These nanometer thin SiC flakes exhibit a high specific surface area of up to $169 \mathrm{~m}^{2} \mathrm{~g}^{-1}$ and a high total pore volume of up to $0.75 \mathrm{~cm}^{3} \mathrm{~g}^{-1}$ - properties which can be finely tuned by the adjustment of the $\mathrm{NaCl} / \mathrm{PCS}$ ratio.

This method is a simple, versatile and robust way for the production of $\mathrm{SiC}$ nanostructures. Such a facile synthetic method could bring nanostructured SiC one step closer to the ultimate goal of practical applications such as in Li-ion batteries, for hydrogen evolution and/or storage, as anticorrosive surfaces, solar cells, fuel cells and other applications.

\section{Acknowledgements}

We are grateful to the Ministry of Education, Science and Sport of the Republic of Slovenia for the financial support through the postdoctoral/early career grant (JR RK-13) "Raziskovalci na začetku kariere". We also acknowledge the financial support of the Slovenian Research Agency Program P2-0377. 


\section{Notes and references}

1 D. H. Van Dorp, N. Hijnen, M. Di Vece and J. J. Kelly, Angew. Chem., Int. Ed., 2009, 48, 6085.

2 J. Fan and P. K. Chu, Small, 2010, 19, 2080.

3 E. S. Saddow, Silicon Carbide Biotechnology: A Biocompatible Semiconductor for Advanced Biomedical Devices and Applications, Elsevier, Amsterdam, 2012.

4 W. H. Backes, P. A. Bobbert and W. van Haeringen, Phys. Rev. B: Condens. Matter Mater. Phys., 1994, 49, 7564.

5 J. Fan and P. K. Chu, Silicon Carbide Nanostructures: Fabrication, Structure, and Properties, Springer International Publishing, Switzerland, 2014.

6 J. Y. Fan, X. L. Wu and P. K. Chu, Prog. Mater. Sci., 2006, 51, 983.

7 J. Fan, H. Li, J. Jiang, L. K. Y. So, Y. W. Lam and P. K. Chu, Small, 2008, 4, 1058.

8 Y. Zakharko, T. Nychyporuk, L. Bonacina, M. Lemiti and V. Lysenko, Nanotechnology, 2013, 24, 055703.

9 X. Lin, S. Lin, Y. Xu, A. Hakro, T. Hasan, B. Zhang, B. Yu, J. Luo, E. Li and H. Chen, J. Mater. Chem. C, 2013, 1, 2131.

10 W. Zhou, L. Yan, Y. Wang and Y. Zhang, Appl. Phys. Lett., 2006, 89, 013105.

11 J.-Y. Hao, Y.-Y. Wang, X. L. Tong, G. Q. Jin and X.-Y. Guo, Int. J. Hydrogen Energy, 2012, 37, 15038.

12 Z. Cheng, F. Bing, Q. Liu, Z. Zhang and X. Fang, J. Mater. Chem. A, 2015, 3, 4652.

13 S. D. T. Kumari, D. Jeyakumar and T. P. Kumar, RSC Adv., 2013, 3, 15028.

14 C. He, X. Wu, J. Shen and P. K. Chu, Nano Lett., 2012, 12, 1545.

15 G. Mpourmpakkis and G. E. Froudakis, Nano Lett., 2006, 8, 1581.

16 M. Wang, J. Chen, X. Liao, Z. Liu, J. Zhang, L. Gao and Y. Li, Int. J. Hydrogen Energy, 2014, 39, 14581.

17 G. Mishra, K. M. Parida and S. K. Singh, ACS Sustainable Chem. Eng., 2015, 3, 245.

18 K. V. Emtsev, A. Bostwick, K. Horn, J. Jobst, G. L. Kellogg, L. Ley, J. L. McChesney, T. Ohta, S. A. Reshanov, J. Röhrl, E. Rotenberg, A. K. Schmid, D. Waldmann, H. B. Weber and T. Seyller, Nat. Mater., 2009, 8, 203.

19 P. Mavinakuli, S. Wei, Q. Wang, A. B. Karki, S. Dhage, Z. Wang, D. P. Young and Z. Guo, J. Phys. Chem. C, 2010, 114, 3874 .

20 Z. Guo, T. Y. Kim, K. Lei, T. Pereira, J. G. Sugar and H. T. Hahn, Compos. Sci. Technol., 2008, 68, 164.

21 J. Chen, J. Zhang, M. Wang and Y. Li, Sens. Actuators, B, 2014, 201, 402.

22 J. Chen, X. Liao, M. Wang, Z. Liu, J. Zhang, L. Ding, L. Gao and Y. Li, Nanoscale, 2015, 7, 6374.

23 S. Yang, W. Cai, H. Zeng and X. Xu, J. Mater. Chem., 2009, 19, 7119.
24 T. Seeger, P. Kohler-Redlich and M. Rühle, Adv. Mater., 2000, $12,279$.

25 Y. Y. Choi and D. J. Choi, CrystEngComm, 2013, 15, 6963.

26 G. W. Meng, Z. Cui, L. D. Zhang and F. Philipp, J. Cryst. Growth, 2000, 209, 801.

27 S. Chabi, H. Chang, Y. Xia and Y. Zhu, Nanotechnology, 2016, 27, 075602.

28 J. Chen, Q. Shi, L. Gao and H. Zhu, Phys. Status Solidi A, 2010, 207, 2483.

29 J. Chen, J. Zhang, M. Wang, L. Gao and Y. Li, J. Alloys Compd., 2014, 65, 168.

30 L. Xin, Q. Shi, J. Chen, W. Tang, N. Wang, Y. Liu and Y. Lin, Mater. Charact., 2012, 65, 55.

31 R. D'Amato, M. Falconieri, S. Gagliardi, E. Popovici, E. Serra, G. Terranova and E. Borsella, J. Anal. Appl. Pyrolysis, 2013, 114, 461.

32 X. Liu, M. Antonietti and C. Giordano, Chem. Mater., 2013, 25, 2021.

33 J. Zhu, Z. Liu, X. L. Wu, L. L. Xu, W. C. Zhang and P. K. Chu, Nanotechnology, 2007, 18, 365603.

34 I. K. Sung, S. B. Yoon, J.-S. Yu and D.-P. Kim, Chem. Commun., 2002, 14, 1480.

35 K.-H. Park, I.-K. Sung and D.-P. Kim, J. Mater. Chem., 2004, 14, 3436.

36 N. Baccile, F. Babonneau, B. Thomas and T. Coradin, J. Mater. Chem., 2009, 19, 8537.

37 E. D. Manev and A. V. Nguyen, Adv. Colloid Interface Sci., 2005, 114-115, 133.

38 P. Scherrer, Nachr. Ges. Wiss. Goettingen, Math.-Phys. Kl., 1918, 1918, 98.

39 E. Bouillon, F. Langlais, E. Pailler, E. Naslain, F. Cruege, J. C. Houng Sarthou, A. Delpuech, C. Laffon, P. Lagarde, M. Monthioux and A. Oberlin, J. Mater. Sci., 1991, 26, 1333.

40 E. J. Olivier and J. H. Neethling, Int. J. Refract. Met. Hard Mater., 2009, 27, 443.

41 U. Lindefelt, H. Iwata, S. Öberg and P. Briddon, Phys. Rev. B: Condens. Matter Mater. Phys., 2003, 67, 155204.

42 A. C. Ferrari and J. Robertson, Philos. Trans. R. Soc., A, 2004, 362, 2477.

43 C. Castiglioni, M. Tommasini and G. Zerbi, Philos. Trans. $R$. Soc., A, 2004, 362, 2425.

44 S. Karlin and P. Colomban, J. Raman Spectrosc., 1997, 28, 219.

45 A. C. Ferrari and J. Robertson, Phys. Rev. B: Condens. Matter Mater. Phys., 2001, 64, 075414.

46 E. Bouillon, F. Langlais, R. Pailler, R. Naslain, F. Cruege and P. V. Huong, J. Mater. Sci., 1991, 26, 1333.

47 G. Wei, W. Qin, K. Zheng, D. Zhang, J. Sun, J. Lin, R. Kim, G. Wang, P. Zu and L. Wang, Cryst. Growth Des., 2009, 9, 1431. 